\title{
Cellulase production using natural medium and its application on enzymatic hydrolysis of thermo chemically pretreated biomass
}

\author{
Shivani Sharma $^{1} \cdot$ Vinay Sharma $^{1} \cdot$ Arindam Kuila $^{1}$
}

Received: 13 April 2016/Accepted: 11 June 2016/Published online: 21 June 2016

(c) The Author(s) 2016. This article is published with open access at Springerlink.com

\begin{abstract}
Lignocellulosic bioethanol is an important renewable fuel for transportation purpose. Commercial production of lignocellulosic bioethanol mainly depends on cost of cellulase production, efficient pretreatment and enzymatic hydrolysis process. In the present study cellulase production from Aspergillus niger under submerged fermentation $(\mathrm{SmF})$ was optimized using coconut water as natural medium. Maximum cellulase production $(0.53 \mathrm{IU} /$ $\mathrm{mL}$ ) was achieved within 3 days of incubation using $8 \%$ (w/v) waste paper and $0.07 \%(w / v)$ glucose. The produced cellulase was applied for enzymatic hydrolysis of thermo chemically (dilute acid and alkaline) pretreated biomass (equal mixture of wheat straw and cotton stalk). Optimization of dilute acid and dilute alkaline pretreatment showed dilute alkaline pretreatment was more effective for higher reducing sugar production. Maximum reducing sugar yield of $398.0 \mathrm{mg} / \mathrm{g}$ dry biomass was obtained from dilute alkaline pretreated biomass (using $0.5 \mathrm{M}$ sodium hydroxide, $8 \%$ substrate concentration, $120{ }^{\circ} \mathrm{C}$ temperature and 20 min of incubation time). The presence of difference sugars (glucose, xylose, mannose, maltose) in the saccharified sample was confirmed by thin layer chromatographic analysis. The effectiveness of dilute alkaline pretreatment was further confirmed by biochemical composition (cellulose, hemicelluloses and lignin) and structural (furrier transformed infrared spectroscopic and scanning electron microscopic) analysis. The above result can be useful for commercial production of lignocellulosic bioethanol.
\end{abstract}

Arindam Kuila

arindammcb@gmail.com

1 Bioscience and Biotechnology Department, Banasthali University, Banasthali 304022, Rajasthan, India
Keywords Lignocellulosic bioethanol · Cellulase · Thermochemical pretreatment $\cdot$ FTIR $\cdot$ SEM

\section{Introduction}

Biofuel production from lignocellulosic biomass has several attractive features such as high availability, no competition with food chain and abundant in supply. Lignocellulosic biomass mainly composed of cellulose, hemicelluloses and lignin. For biofuel production, there needs hydrolysis of carbohydrates (cellulose and hemicelluloses) portion of lignocellulosic biomass (Khare et al. 2015). Prior to hydrolysis most lignocellulosic substrates need to undergo some sort of pretreatment to enhance the accessibility of the substrate for efficient hydrolysis and biofuel production. Thermo chemical pretreatment is one such process. It has several advantages such as efficient lignin removal within shorter incubation time and high sugar yield (Chen et al. 2013; Singh and Trivedi 2013). Akanksha et al. (2014) reported optimization of dilute acid pretreatment of sorghum biomass. They found maximum reducing sugar yield ( $0.408 \mathrm{~g}$ reducing sugar/g of biomass) when biomass was pretreated using $0.37 \%$ sulphuric acid at $150{ }^{\circ} \mathrm{C}$ for 15 min. McIntosh and Vancov (2011), reported enzymatic hydrolysis of dilute alkaline pretreated wheat straw. Pretreating biomass using $2 \%$ sodium hydroxide for $30 \mathrm{~min}$ at $121{ }^{\circ} \mathrm{C}$, increased the reducing sugar yield up to 6.3 fold compared to control biomass. After pretreatment, enzymatic hydrolysis is the second step for lignocellulosic biofuel production. Cellulases are used for enzymatic hydrolysis of plant carbohydrate polymers. It is a hydrolytic enzyme that degrades cellulose to glucose. Several authors reported on enzymatic hydrolysis of different types of lignocellulosic biomass (Nitsos et al. 2013; Bals et al. 2014; 
Maitan-Alfenas et al. 2015). But major drawback on large scale trial of enzymatic hydrolysis of lignocellulosic biomass is the cost of cellulase enzyme. Till now there is no viable technology which can produce cellulase in cost effective manner. For cheaper cellulase production, high cost of medium constituent is major limiting factor. In such case, coconut water can be used as cheaper alternative for higher cellulase production. Major constituents of coconut water are total sugar $32 \mathrm{~g} / \mathrm{L}$, glucose $13.5 \mathrm{~g} / \mathrm{L}$, protein $5.5 \mathrm{~g} / \mathrm{L}$, calcium $7 \mathrm{mmol} / \mathrm{L}$, magnesium $3.4 \mathrm{mmol} / \mathrm{L}, \mathrm{pH}$ 5.6 (Vigliar et al. 2006; Prades et al. 2012).

Previously several authors worked on cellulase production under solid state fermentation (SSF) in cost effective manner (Gupta et al. 2015; Kuila et al. 2015; Mangalanayaki and Madhavan 2015). Although SSF has several advantages for higher cellulase production, but it has different drawbacks for large scale enzyme production such as require large space for enzyme production, less amount of enzyme are extracted after fermentation, purification of enzyme is difficult etc. In such case, submerged fermentation $(\mathrm{SmF})$ are used for production of several industrially important enzymes (cellulase, xylanase, laccase etc.) due to its several advantages such as greater control of environmental factors (temperature, $\mathrm{pH}$ ), require less number of space, higher amount of enzyme can be extracted after fermentation, purification of the enzyme is easier.

In the present investigation, equal mixture of wheat straw and cotton stalk (abundantly available in India) were used for optimization of thermo chemical pretreatment (dilute acid and alkaline). After that, enzymatic hydrolysis was carried out using pretreated biomass. Enzyme production was optimized under submerged fermentation (SmF) using natural medium (coconut water) and waste paper. According to our knowledge, this is the first report on cellulase production under $\mathrm{SmF}$ using coconut water (highly available in India) as growth medium.

\section{Materials and methods}

\section{Biomass}

Wheat straw and cotton stalk collected from nearby locality of Banasthali University, Rajasthan. Both the substrates were dried overnight at $70{ }^{\circ} \mathrm{C}$. Dried substrates were milled to particle size less than $0.2 \mathrm{~mm}$. After that both the milled substrates were mixed in equal proportion and further used for thermo chemical pretreatment.

\section{Cellulase production}

Cellulase production was carried out under submerged fermentation in $250 \mathrm{ml}$ Erlenmeyer flask which contained $100 \mathrm{~mL}$ of sterile medium. The composition of the medium was: coconut water and varying concentration of waste news paper. A small spore suspension $\left(1 \times 10^{7}\right.$ spores/mL) of Aspergillus niger MS82 agar slant was added to the $100 \mathrm{~mL}$ sterile medium. Cellulase assay (FPase) was carried out by following standard assay protocol (Nathan et al. 2014). The cellulase production experiment was focused on FPase activity, produced by Aspergillus niger and further optimized using central composite design (CCD) based response surface methodology (RSM). The parameters and their ranges were: glucose concentration $(0.025-$ $0.075 \%, \mathrm{w} / \mathrm{v})$, waste news paper concentration $(2-8 \%$, w/v) and incubation time (3-5 days). Total 20 runs were carried out for optimization study. Each experiment was carried out in triplicates. After optimization of cellulase production, it was further used for enzymatic hydrolysis of pretreated substrate.

\section{Thermo chemical pretreatment of biomass}

The mixture of biomass was thermo chemically pretreated using dilute sulphuric acid and sodium hydroxide. For optimization study the parameters varied were: biomass concentration $(1-10 \%, \mathrm{w} / \mathrm{v})$, sulphuric acid/sodium hydroxide concentration (0.1-1 M) and incubation time (5-40 min). After each type of pretreatment biomass was washed with distilled water and then dried overnight at $70{ }^{\circ} \mathrm{C}$. After that dried biomass was subsequently used for enzymatic hydrolysis experiments.

\section{Biochemical composition analysis of biomass}

Biochemical composition (extractives, cellulose, hemicelluloses and lignin) of raw and optimum pretreated (sodium hydroxide pretreated) biomass were determined by following the procedure of Yang et al. (2006). In this procedure, biomass was extracted with acetone. The amount of extractives was measured as weight difference of the biomass before and after extraction. To determine hemicelluloses content, the extractive free biomass was treated with $0.5 \mathrm{M}$ sodium hydroxide. The weight difference before and after sodium hydroxide treatment was the hemicelluloses content. To determine lignin content, extractive free biomass was treated with sulphuric acid (98\%). The weight difference before and after sulphuric acid treatment was the lignin content. The weight difference of the initial biomass and total lignin, hemicelluloses and extractive content was calculated as cellulose content of the biomass (assuming that biomass contains only cellulose, hemicelluloses, lignin and extractives). 


\section{Enzymatic hydrolysis of pretreated biomass}

Enzymatic hydrolysis was carried out under following conditions: pretreated substrate loading: $2.5 \%$, cellulase enzyme loading: $20 \mathrm{FPU} / \mathrm{g}$ dry substrate, temperature: $50{ }^{\circ} \mathrm{C}$ and incubation time: $24 \mathrm{~h}$. After enzymatic hydrolysis, samples were withdrawn and centrifuges at $5000 \mathrm{rpm}$ for $10 \mathrm{~min}$. After that supernatant were collected separately and measured for reducing sugar by following miller method (Miller 1959).

\section{Fourier transformed infrared spectroscopy (FTIR) study}

FTIR study was carried out in control and pretreated (sodium hydroxide pretreated) biomass using $\mathrm{KBr}$ pellet technique. Sample spectra were taken in the range of 600 and $4000 \mathrm{~cm}^{-1}$ with the spectral resolution of $0.5 \mathrm{~cm}^{-1}$.

\section{Field emission scanning electron microscopy (FESEM) study}

FESEM (Mira 3, Tescan, field emission scanning electron microscope) was carried out in both the control and pretreated (sodium hydroxide pretreated) biomass. Before FESEM analysis samples were dried and coated with gold.

\section{Thin layer chromatography (TLC) analysis}

TLC analysis of saccharified sample of pretreated biomass (sodium hydroxide pretreated) was carried out using TLC plate. The mobile phage used was ethyl acetate, isopropanol, water and pyridine (26:14:7:2). After complete run plat was dried and sugar spots were detected with aniline diphenylamine reagent. The sugar spots were detected against various standard sugars (glucose, xylose, mannose, maltose, ribose and arabinose). For TLC analysis, samples were prepared in absolute ethanol in a ratio of $3: 1$ and then centrifuged for the separation of any residual protein.

\section{Result and discussion}

\section{Optimization of cellulase production using CCD based RSM}

Cellulase production under submerged fermentation was optimized using CCD based RSM. Table 1 showed the experimental design and response for cellulase production.

Interactive effect of the independent variables (glucose concentration, waste news paper concentration and incubation time) was investigated to obtain optimum conditions of cellulase production. ANOVA analysis (Table 2) carried
Table 1 Experimental design and responses for cellulase production by Aspergillus niger

\begin{tabular}{|c|c|c|c|c|c|}
\hline \multirow[t]{2}{*}{ Run order } & \multirow{2}{*}{$\begin{array}{l}\text { Glucose } \\
\text { concentration }(\%)\end{array}$} & \multirow{2}{*}{$\begin{array}{l}\text { Substrate } \\
\text { concentration }(\%)\end{array}$} & \multirow{2}{*}{$\begin{array}{l}\text { Incubation } \\
\text { time (days) }\end{array}$} & \multicolumn{2}{|c|}{ Cellulase activity (IU/mL) } \\
\hline & & & & Experimental & Predicted \\
\hline 1 & 0.025 & 2 & 3 & 0.28 & 0.26 \\
\hline 2 & 0.075 & 2 & 3 & 0.30 & 0.31 \\
\hline 3 & 0.025 & 8 & 3 & 0.34 & 0.34 \\
\hline 4 & 0.075 & 8 & 3 & 0.51 & 0.49 \\
\hline 5 & 0.025 & 2 & 5 & 0.41 & 0.42 \\
\hline 6 & 0.075 & 2 & 5 & 0.16 & 0.15 \\
\hline 7 & 0.025 & 8 & 5 & 0.37 & 0.36 \\
\hline 8 & 0.075 & 8 & 5 & 0.18 & 0.19 \\
\hline 9 & 0.025 & 5 & 4 & 0.38 & 0.39 \\
\hline 10 & 0.075 & 5 & 4 & 0.33 & 0.33 \\
\hline 11 & 0.05 & 2 & 4 & 0.37 & 0.37 \\
\hline 12 & 0.05 & 8 & 4 & 0.42 & 0.43 \\
\hline 13 & 0.05 & 5 & 3 & 0.38 & 0.41 \\
\hline 14 & 0.05 & 5 & 5 & 0.35 & 0.34 \\
\hline 15 & 0.05 & 5 & 4 & 0.40 & 0.41 \\
\hline 16 & 0.05 & 5 & 4 & 0.41 & 0.41 \\
\hline 17 & 0.05 & 5 & 4 & 0.42 & 0.41 \\
\hline 18 & 0.05 & 5 & 4 & 0.42 & 0.41 \\
\hline 19 & 0.05 & 5 & 4 & 0.43 & 0.41 \\
\hline 20 & 0.05 & 5 & 4 & 0.40 & 0.41 \\
\hline
\end{tabular}


Table 2 ANOVA of RSM model for for cellulase production by Aspergillus niger

\begin{tabular}{|c|c|c|c|c|c|c|}
\hline Source & $\mathrm{DF}^{\mathrm{a}}$ & Seq $\mathrm{SS}^{\mathrm{b}}$ & Adj $S^{b}$ & Adj $\mathrm{MS}^{\mathrm{c}}$ & $F$ & $P$ \\
\hline Regression & 9 & 0.12784 & 0.12784 & 0.01421 & 44.71 & $<0.001$ \\
\hline Linear & 3 & 0.02956 & 0.05830 & 0.01943 & 61.17 & $<0.001$ \\
\hline Square & 3 & 0.03265 & 0.03265 & 0.01088 & 34.25 & $<0.001$ \\
\hline Interaction & 3 & 0.06564 & 0.06564 & 0.02188 & 68.87 & $<0.001$ \\
\hline Residual error & 10 & 0.00318 & 0.00318 & 0.00032 & & \\
\hline Lack-of-fit & 5 & 0.00244 & 0.00244 & 0.00049 & 03.33 & 0.106 \\
\hline Pure error & 5 & 0.00073 & 0.00073 & 0.00015 & & \\
\hline Total & 20 & 0.13102 & & & & \\
\hline$R^{2}$ & $97.58 \%$ & $95.39 \%$ & & & & \\
\hline
\end{tabular}

${ }^{\text {a Degree of freedom }}$

b Sum of squares

${ }^{c}$ Mean squares

out that gave following second order polynomial model by response surface regression method (Mukhopadhyay et al. 2011):

Cellulase activity $(\mathrm{IU} / \mathrm{mL})$

$=-1.0349+17.21 \times$ glucose concentration +0.05

$\times$ substrate concentration

$+0.48 \times$ incubation time -75.64

$\times$ glucose concentration $\times$ glucose concentration

$-0.04 \times$ incubation time $\times$ incubation time

$+0.35 \times$ glucoseconcentration

$\times$ substrate concentration $-3.15 \times$ glucose concentration

$x$ incubation time

$-0.01 \times$ substrate concentration $\times$ incubation time

where, cellulase activity $(\mathrm{IU} / \mathrm{mL})$ is response, glucose concentration, substrate concentration and incubation time are uncoded independent variables.

From ANOVA Table it was found that the $F$ value was 44.71 and $P$ value was $<0.001$ at 9 degree of freedom. The obtained $F$ value was lesser than table $F$ value and consequent $P$ value was very less (less than 0.05 ), which showed that the RSM model adequately describe the relationship between the response (cellulase activity) and the independent variables. Further, the observed and adjusted regression coefficient $\left(R^{2}\right)$ values were 97.58 and $95.39 \%$, respectively. This demonstrated that the present model was capable of describing maximum variation in the data.

The interactive effect of independent variables was observed using 3D response surface plot analysis. Each figure represents the effect of two different independent variables on cellulase production while other parameters kept constant at its optimum point. Figure 1 showed the effect of substrate concentration and incubation time on cellulase production from Aspergillus niger. It demonstrated by increasing substrate concentration along with incubation time cellulase activity was increased and maximum cellulase activity $(0.53 \mathrm{IU} / \mathrm{mL})$ was obtained using $8 \%$ substrate concentration and after 3 days of incubation time. After 3 days of incubation time, further increase in incubation time cellulase production was decreased significantly. Damisa et al. (2012) reported cellulase production under submerged fermentation using waste paper as substrate. Authors reported maximum cellulase activity $(0.18 \mathrm{IU} / \mathrm{mL})$ after $96 \mathrm{~h}$ of incubation. The difference in cellulase activity was might be due to different strain and fermentation medium used for cellulase production. Manglanayaki and Madhavan (2015) reported maximum cellulase production $(0.76 \mathrm{IU} / \mathrm{mL})$ using $3 \%$ substrate concentration after 9 days of incubation. Figure 2 demonstrated the effect of glucose and substrate concentration on cellulase production. It showed maximum cellulase activity was obtained using $0.07 \%(\mathrm{w} / \mathrm{v})$ glucose concentration. Interactive effect of glucose concentration and incubation time on cellulase production has been demonstrated in Fig. 3. It showed by increasing glucose concentration along with incubation time cellulase activity was increased but after certain value further increase or decrease its concentration cellulase production was decreased. From 3D response surface plot analysis, the optimum predicted conditions for cellulase production was: glucose concentration $0.07 \%(\mathrm{w} / \mathrm{v})$, substrate concentration $8 \%(\mathrm{w} / \mathrm{v})$ and incubation time 3 days. Under above conditions maximum experimental cellulase activity was found to be $0.53 \mathrm{IU} / \mathrm{mL}$, which was very close to predicted response (0.54 IU/mL). Kumar et al. (2011) reported maximum Aspergillus cellulase production $(0.36 \mathrm{IU} / \mathrm{mL})$ under following conditions: substrate concentration $6.5 \%$, pH 4.6 and incubation time $126 \mathrm{~h}$. Saini et al. (2015) reported 
Fig. 1 RSM plot showing the effect of substrate concentration (\%) and incubation time (days) on cellulase production (IU/mL)
Fig. 2 RSM plot showing glucose concentration $(\%)$ and substrate concentration $(\%)$ on cellulase production $(\mathrm{IU} / \mathrm{mL})$

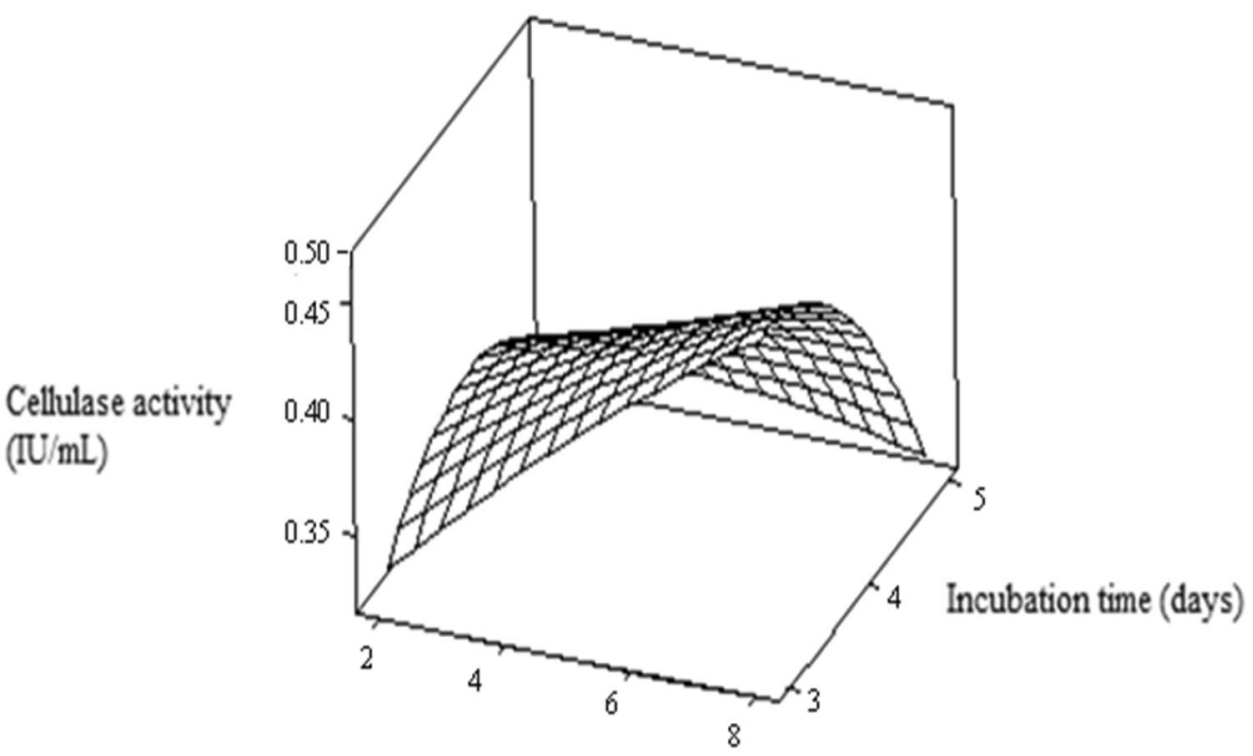

Substrate concentration (\%)

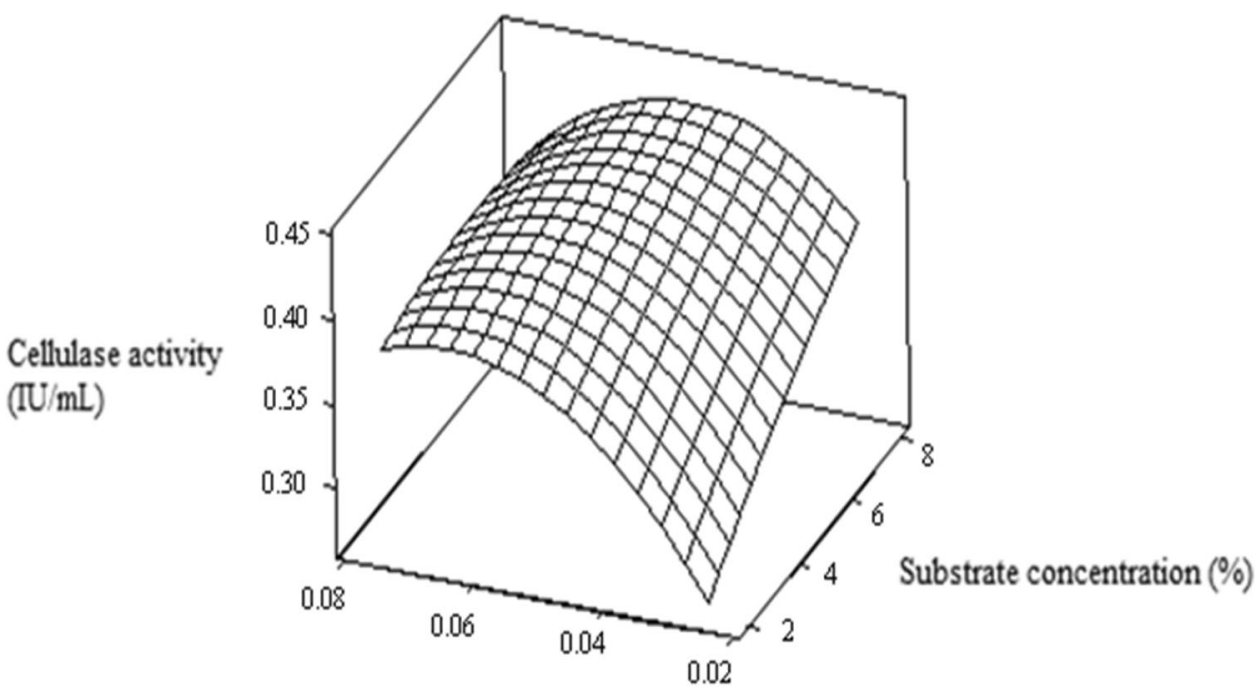

Glucose concentration (\%) cellulase production from Penicillium oxalicum under submerged fermentation. Authors reported maximum cellulase production of $1.2 \mathrm{IU} / \mathrm{mL}$ from after 8 days of incubation using complex growth medium. In the present investigation, maximum cellulase production of $0.53 \mathrm{IU} /$ $\mathrm{mL}$ was obtained within 3 days incubation time using coconut water as growth medium. For cost effective cellulase production medium constituents and incubation time are the major limiting factors (Gautam et al. 2011). The present investigation can be further studied by gradual scaling up of cellulase production for additional enhancement of enzyme production. After optimization of cellulase production, the cellulase was used for enzymatic hydrolysis of pretreated biomass.

\section{Biochemical composition of lignocellulosic biomass}

Table 3 showed biochemical composition of raw and pretreated (sodium hydroxide pretreated) biomass. It showed that after pretreatment lignin and hemicelluloses content decreased considerably but there was no significant effect on cellulose content. This observation was might be due to selective degradation of lignin and hemicelluloses after alkaline pretreatment. Similar type of observation was 
Fig. 3 RSM plot showing glucose concentration (\%) and incubation time (days) on cellulase production $(\mathrm{IU} / \mathrm{mL})$

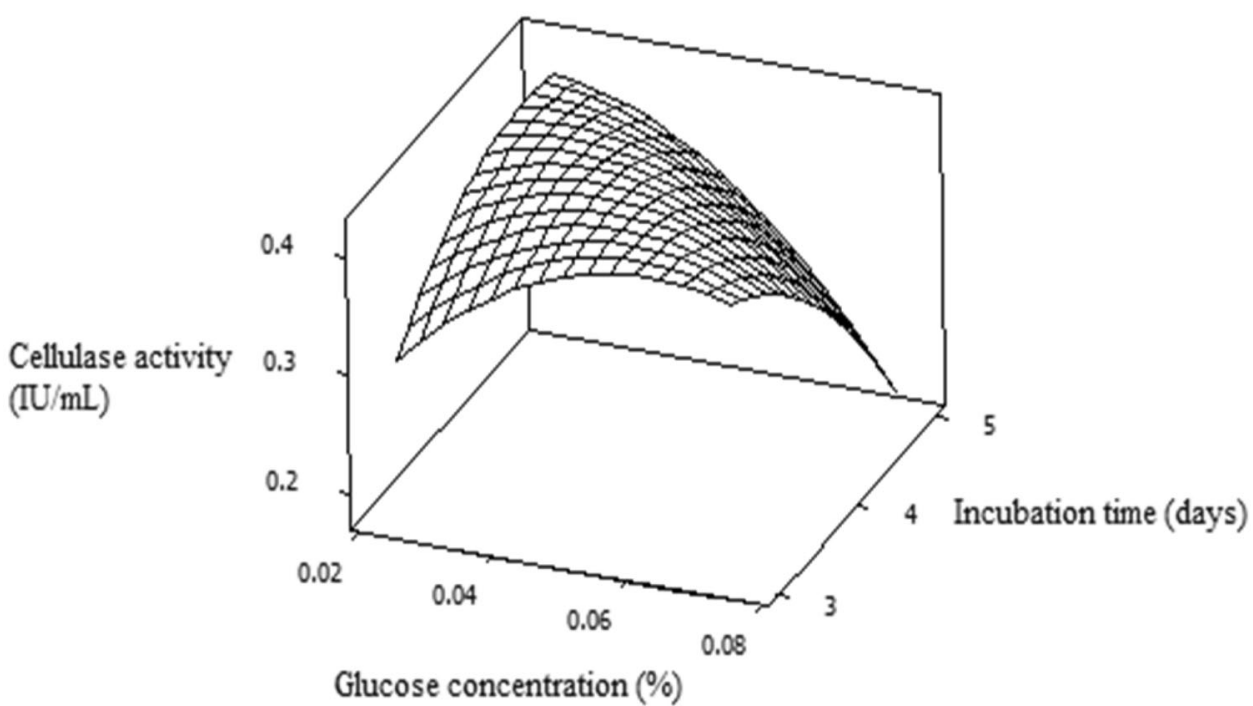

Table 3 Biochemical composition of lignocellulosic biomass

\begin{tabular}{llll}
\hline Biomass type & Cellulose (\%) & Hemicellulose & Lignin (\%) \\
\hline Lignocellulosic biomass (raw) & 38.5 & 22.0 & 18.95 \\
Lignocellulosic biomass (dilute sodium hydroxide pretreated) & 40.02 & 15.06 & 10.25 \\
\hline
\end{tabular}

Fig. 4 Effect of substrate concentration $(\%)$ on thermochemical pretreatment of lignocellulosic biomass (constant values: acid/alkali concentration: $0.2 \mathrm{M}$, temperature, $120{ }^{\circ} \mathrm{C}$, incubation time: $20 \mathrm{~min}$ )

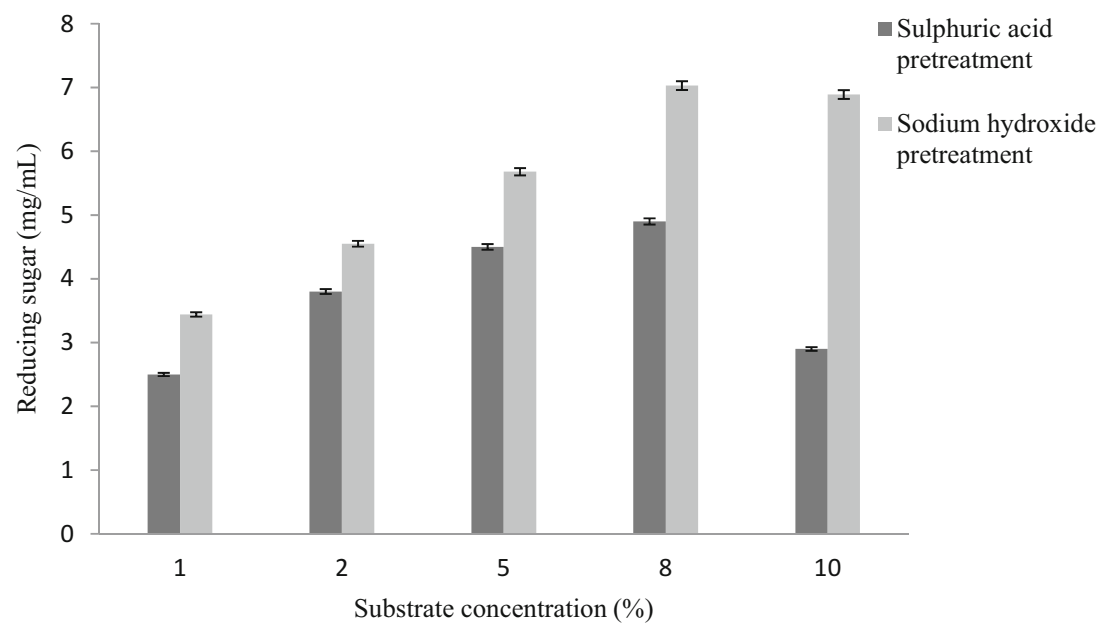

reported previously in case of sodium hydroxide treated corn stover (Chen et al. 2013). For enhanced enzymatic hydrolysis, there needs low lignin content and high cellulose content. The present result showed effectiveness of dilute alkaline pretreatment for efficient hydrolysis of lignocellulosic biomass.

\section{Pretreatment of lignocellulosic biomass}

In the present study dilute acid and alkaline pretreatment of lignocellulosic biomass was carried out under varying conditions of substrate concentration $(1,2,5,8$ and $10 \%)$, dilute acid/alkaline concentration $(0.1,0.2,0.5,0.8$ and $1 \mathrm{M})$ and incubation time (5, 10, 20, 30 and $40 \mathrm{~min}$ ). Figure 4 showed the effect of different substrate concentration on thermochemical pretreatment of lignocellulosic biomass. It showed maximum reducing sugar $(7.03 \mathrm{mg} /$ $\mathrm{mL}$ ) was obtained in case of biomass pretreatment with $0.2 \mathrm{M}$ sodium hydroxide at $8 \%$ substrate concentration, 20 min incubation time and $120{ }^{\circ} \mathrm{C}$ temperature. Further increase or decrease in substrate concentration during thermochemical pretreatment, reducing sugar yield was 
Fig. 5 Effect of acid/alkali concentration (M) on thermochemical pretreatment of lignocellulosic biomass (constant values: substrate concentration: $5 \%$, temperature, $120{ }^{\circ} \mathrm{C}$, incubation time: $20 \mathrm{~min}$ )

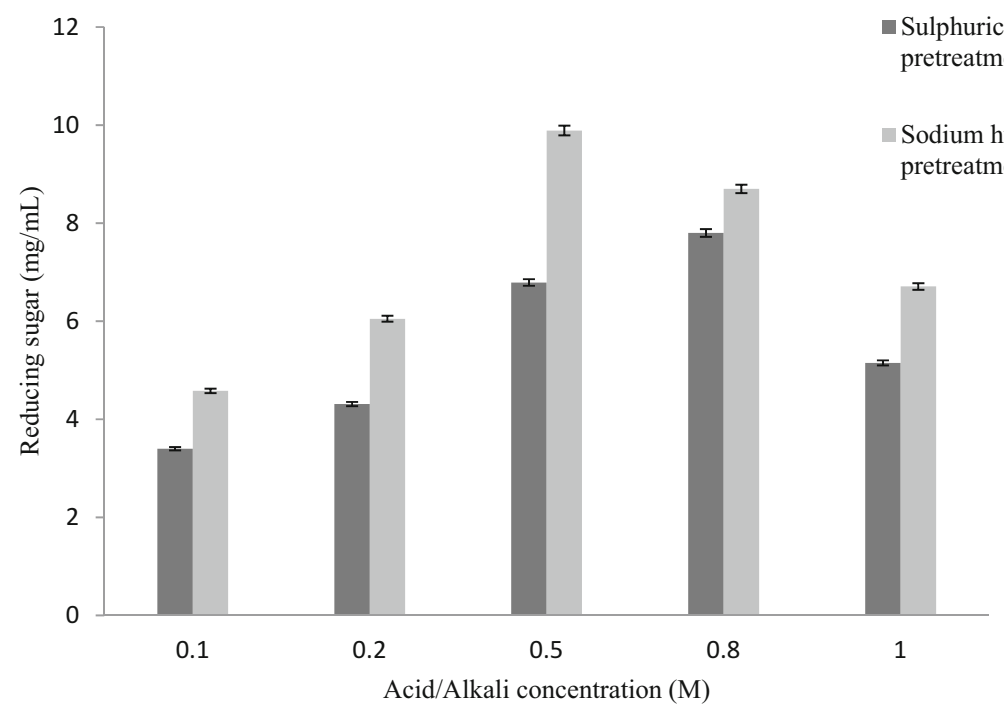

Fig. 6 Effect of incubation time $(\mathrm{min})$ on thermochemical pretreatment of lignocellulosic biomass (constant values: substrate concentration $5 \%$, acid/alkali concentration: $0.5 \mathrm{M}$, and temperature, $\left.120^{\circ} \mathrm{C}\right)$

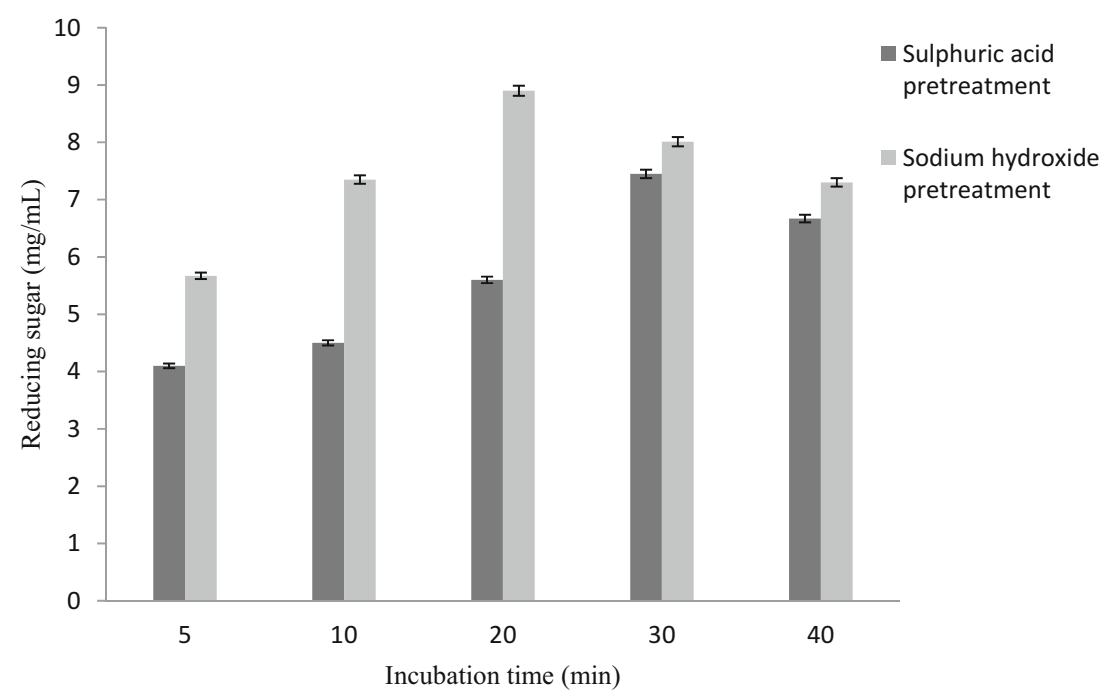

decreased. Similar type of observation was reported by Hong et al. (2012) and McIntosh and Vancov (2011) in case of biomass pretreated with dilute phosphoric acid and sodium hydroxide, respectively. Figure 5 demonstrated the effect of acid/alkaline concentration on thermochemical pretreatment of biomass. It showed maximum reducing sugar $(9.89 \mathrm{mg} / \mathrm{mL})$ was obtained in case of biomass pretreated with $0.5 \mathrm{M}$ sodium hydroxide using $8 \%$ substrate concentration, 20 min incubation time and $120{ }^{\circ} \mathrm{C}$ temperature. Wang et al. (2010) reported sodium hydroxide pretreatment of Bermuda grass. Authors reported maximum reducing sugar production when the biomass was pretreated with $0.19 \mathrm{M}$ sodium hydroxide for $15 \mathrm{~min}$ at $121{ }^{\circ} \mathrm{C}$. The variation in optimum sodium hydroxide concentration was might be due to different biomass was used for pretreatment. Effect of incubation time on thermochemical pretreatment of biomass has been demonstrated in Fig. 6. The maximum reducing sugar $(8.9 \mathrm{mg} / \mathrm{mL})$ was obtained when biomass was treated with $0.5 \mathrm{M}$ sodium hydroxide at $8 \%$ substrate concentration, 20 min incubation time and $120{ }^{\circ} \mathrm{C}$ temperature. Choi et al. (2013) reported optimum sodium hydroxide pretreatment of empty fruit bunch at $3 \%$ sodium hydroxide concentration, $11 \mathrm{~min}$ $20 \mathrm{~s}$ incubation time and $140{ }^{\circ} \mathrm{C}$ temperature. The above results showed that optimum thermochemical pretreatment condition was $0.5 \mathrm{M}$ sodium hydroxide concentration, $8 \%$ substrate concentration, $20 \mathrm{~min}$ incubation time and $120{ }^{\circ} \mathrm{C}$ temperature. The maximum reducing sugar yield from pretreated biomass (under optimum conditions) was $398.0 \mathrm{mg} / \mathrm{g}$ dry biomass within 24 of enzymatic hydrolysis. Kshirsagar et al. (2015) reported maximum reducing sugar yield $(359 \mathrm{mg} / \mathrm{g}$ dry biomass) from dilute acid pretreated rice straw after $72 \mathrm{~h}$ enzymatic hydrolysis. Ioelovich and Morag (2012) reported $82 \%$ reducing sugar yield from mild acid and alkaline pretreated biomass after $48 \mathrm{~h}$ of enzymatic hydrolysis. The present study showed higher 
Fig. 7 FTIR spectra of lignocellulosic biomass (raw and pretreated)

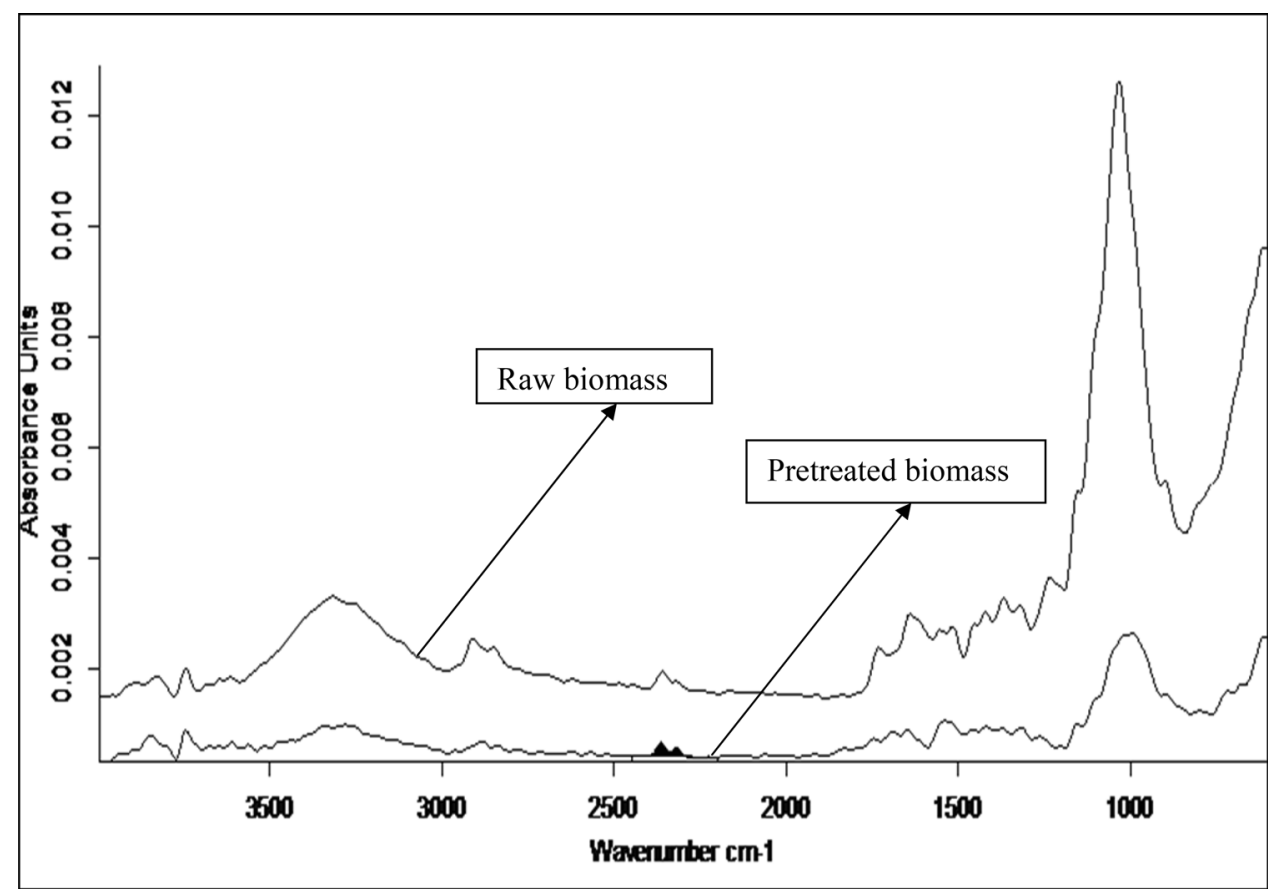

Table 4 FTIR band and corresponding groups present in lignocellulosic biomass (Bodirlau et al. 2009; Xu et al. 2013; Nakashima et al. 2016)

\begin{tabular}{lll}
\hline Wave number $\left(\mathrm{cm}^{-1}\right)$ & Functional group & Remark \\
\hline 1032 & C-H deformation & Present in lignin \\
1693 & Aromatic ring & Present in lignin \\
1745 & Stretching asymmetric and symmetric vibration of $\mathrm{CO}_{2}$ & Present in lignin and cellulose \\
2360 & C-H stretching & Present in lignin \\
2884 & & Present in lignin and hemicellulose \\
3318,3815 & O-H stretching &
\end{tabular}

reducing sugar production from mixture of biomass (wheat straw and cotton stalk) within short incubation time $(24 \mathrm{~h})$. This study has also established that the cheap substrates could effectively be used for ethanol production through further process optimization of simultaneous saccharification and fermentation.

\section{FTIR analysis of lignocellulosic biomass}

FTIR spectral characterization of raw and sodium hydroxide pretreated lignocellulosic biomass was carried out in the region range of $600-4000 \mathrm{~cm}^{-1}$. Figure 7 showed the IR spectra of raw and pretreated biomass. The peak around $1032 \mathrm{~cm}^{-1}$ corresponds to aromatic $\mathrm{C}-\mathrm{H}$ deformation (present in lignin), $\mathrm{C}-\mathrm{O}$ deformation in primary alcohol and stretching of non conjugated $\mathrm{C}=\mathrm{O}$ bond (lignin and hemicelluloses). The band around $1693 \mathrm{~cm}^{-1}$ corresponds to un-conjugated $\mathrm{C}-\mathrm{O}$ stretching (present in lignin) and band around $2838-2911 \mathrm{~cm}^{-1}$ corresponds to $\mathrm{C}-\mathrm{H}$ stretching of lignin polymer. The band around 3318 and $3815 \mathrm{~cm}^{-1}$ corresponds to $\mathrm{O}-\mathrm{H}$ stretching of lignin and hemicelluloses polymer. Table 4 summarizes the absorbance band and corresponding functional groups present in lignocellulosic biomass. All the band intensities were reduced after sodium hydroxide pretreatment, indicates the degradation of lignin polymer during pretreatment. The reduced intensity indicates cleavage of lignin side chains. The above result highlight the effectiveness of dilute alkaline pretreatment of lignocellulosic biomass for enzymatic hydrolysis.

\section{SEM analysis of lignocellulosic biomass}

Figure 8 showed the SEM picture of raw and pretreated (sodium hydroxide pretreated lignocellulosic biomass. It showed after pretreatment the cell wall structure of lignocellulosic biomass was degraded. This finding demonstrated that degradation of lignin and hemicelluloses during pretreatment cause distortion of cell wall structure of lignocellulosic biomass. Similar types of observation were 
Fig. 8 SEM image of

lignocellulosic biomass (raw and pretreated)
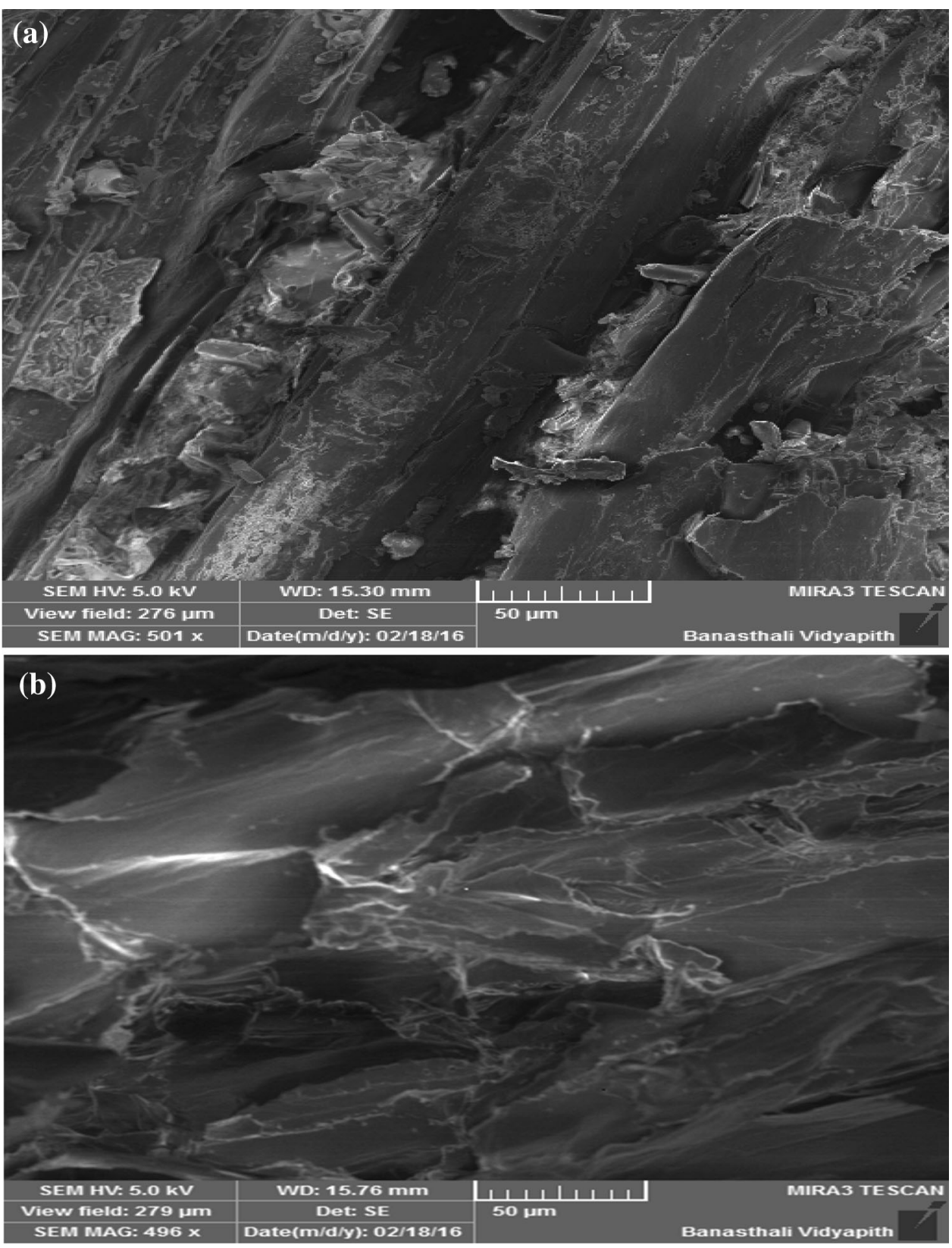

reported earlier (Cui et al. 2012; Wei et al. 2015). The SEM analysis demonstrated the effectiveness of dilute alkaline pretreatment for efficient saccharification of lignocellulosic biomass.

\section{TLC analysis of sugars present in saccharified sample of pretreated biomass}

Sugars present in the saccharified sample were analyzed by calculating their $R_{\mathrm{f}}$ value (Table 5). The result suggested the presence of different sugars (glucose, xylose, mannose, maltose) in the saccharified sample.
Table $5 \mathrm{R}_{\mathrm{f}}$ values of sugars present in saccharified sample

\begin{tabular}{lll}
\hline Sugars & $\begin{array}{l}R_{\mathrm{f}} \text { values of } \\
\text { standard sugars }\end{array}$ & $\begin{array}{l}R_{\mathrm{f}} \text { values of sugars } \\
\text { present in saccharified } \\
\text { sample }\end{array}$ \\
\hline Xylose & 0.872 & 0.872 \\
Ribose & 0.672 & - \\
Arabinose & 0.590 & - \\
Mannose & 0.551 & 0.551 \\
Glucose & 0.456 & 0.456 \\
Maltose & 0.321 & 0.321 \\
\hline
\end{tabular}




\section{Conclusion}

The present study deals with optimization of cellulase production under submerged fermentation using natural medium and waste paper. Maximum cellulase production $(0.53 \mathrm{IU} / \mathrm{mL})$ was obtained within 3 days of incubation time. The produced cellulase was applied for hydrolysis of dilute acid and alkaline pretreated biomass. It showed maximum reducing sugar yield of $398.0 \mathrm{mg} / \mathrm{g}$ dry biomass was obtained from dilute alkaline pretreated biomass (under sodium hydroxide concentration of $0.5 \mathrm{M}$, substrate concentration of $8 \%$, temperature of $120{ }^{\circ} \mathrm{C}$ and incubation time of $20 \mathrm{~min}$ ). Further effectiveness of dilute alkaline pretreatment was analyzed through FTIR and SEM study.

Acknowledgments Authors sincerely acknowledge Prof. Aditya Shastri, Vice Chancellor, Banasthali University for research facilities and infrastructure.

\section{Compliance with ethical standards}

Conflict of interest The authors declare that they have no conflict of interest in the publication.

Open Access This article is distributed under the terms of the Creative Commons Attribution 4.0 International License (http:// creativecommons.org/licenses/by/4.0/), which permits unrestricted use, distribution, and reproduction in any medium, provided you give appropriate credit to the original author(s) and the source, provide a link to the Creative Commons license, and indicate if changes were made.

\section{References}

Akanksha K, Prasad A, Sukumaran RK, Nampoothiri MK, Pandey A, Rao SS, Parameswaran B (2014) Dilute acid pretreatment and enzymatic hydrolysis of sorghum biomass for sugar recovery-a statistical approach. Ind J Exp Bio 52:1082-1089

Bals BD, Gunawan C, Moore J, Teymouri F, Dale BE (2014) Enzymatic hydrolysis of pelletized afex (tm)-treated corn stover at high solid loadings. Biotechnol Bioeng 111:264-271

Bodirlau R, Teaca CA, Spiridon I (2009) Pretreatment and characterization of composites comprising modified hardwood and wood polymers/poly (vinyl chloride). BioResources 4:1285-1304

Chen Y, Stevens MA, Zhu Y, Holmes J, Xu H (2013) Understanding of alkaline pretreatment parameters for corn stover enzymatic saccharification. Biotechnol Biofuel 6:1-10

Choi W, Park JY, Lee JP, Oh YK, Park YC, Kim JS, Park JM, Kim $\mathrm{CH}$, Lee JS (2013) Optimization of $\mathrm{NaOH}$-catalyzed steam pretreatment of empty fruit bunch. Biotechnol Biofuel 6:1-8

Cui L, Liu Z, Si C, Hui L, Kang N, Zhao T (2012) Influence of steam explosion pretreatment on the composition and structure of wheat straw. BioResources 7:4202-4213

Damisa D, Sule EI, Moneme S (2012) Cellulase production from waste paper using Trichoderma species isolated from rhizospheric soil. Afr J Biotechnol 11:16342-16346

Gautam SP, Bundela PS, Pandey AK, Khan J, Awasthi MK, Sarsaiya S (2011) Optimization for the production of cellulase enzyme from municipal solid waste residue by two novel cellulolytic fungi. Biotechnol Res Int 2011:1-8

Gupta C, Jain P, Kumar D, Dixit AK, Jain RK (2015) Production of cellulase enzyme from isolated fungus and its application as efficient refining aid for production of security paper. Int $\mathbf{J}$ Appl Microbiol Biotechnol Res 3:11-19

Hong B, Xue G, Weng L, Guo X (2012) Pretreatment of moso bamboo with dilute phosphoric acid. Bioresources 7:4902-4913

Ioelovich M, Morag E (2012) Study of enzymatic hydrolysis of mild pretreated lignocellulosic biomasses. BioResources 7:1040-1052

Khare SK, Pandey A, Larroche C (2015) Current perspectives in enzymatic saccharification of lignocellulosic biomass. Biochem Eng J 102:38-44

Kshirsagar SD, Waghmare PR, Loni PC, Patil SA, Govindwar SP (2015) Dilute acid pretreatment of rice straw, structural characterization and optimization of enzymatic hydrolysis conditions by response surface methodology. RSC Adv 5:46525-46533

Kuila A, Rao PVC, Choudary NV, Sriganesh G, Velankar HR (2015) Novel natural supplement for the production of fungal cellulases and application for enzymatic saccharification of wheat straw. Environ Prog Sustain Energ 34:1243-1248

Kumar S, Sharma HK, Sarkar BC (2011) Effect of substrate and fermentation conditions on pectinase and cellulase production by Aspergillus niger NCIM 548 in submerged (SmF) and solid state fermentation (SSF). Food Sci Biotechnol 20:1289-1298

Maitan-Alfenas GP, Visser EM, Guimarães VM (2015) Enzymatic hydrolysis of lignocellulosic biomass: converting food waste in valuable products. Curr Opin Food Sci 1:44-49

Mangalanayaki R, Madhavan S (2015) Cellulase production by Trichoderma harzianum and Fusarium oxysporum under solid state fermentation. WJPPS 4:1822-1828

McIntosh S, Vancov T (2011) Optimisation of dilute alkaline pretreatment for enzymatic saccharification of wheat straw. Biomass Bioenerg 35:3094-3103

Miller GL (1959) Use of dinitrosalicylic acid reagent for determination of reducing sugar. Anal Chem 31:426-428

Mukhopadhyay M, Kuila A, Tuli DK, Banerjee R (2011) Enzymatic depolymerization of Ricinus communis, a potential lignocellulosic for improved saccharification. Biomass Bioenerg 35:3584-3591

Nakashima K, Ebi Y, Shibasaki-Kitakawa N, Soyama H (2016) Hydrodynamic cavitation reactor for efficient pretreatment of lignocellulosic biomass. Ind Eng Chem Res 55:1866-1871

Nathan VK, Rani ME, Rathinasamy G, Dhiraviam KN, Jayavel S (2014) Process optimization and production kinetics for cellulase production by Trichoderma viride VKF3. SpringerPlus 3:1-12

Nitsos CK, Matis KA, Triantafyllidis KS (2013) Optimization of hydrothermal pretreatment of lignocellulosic biomass in the bioethanol production process. ChemSusChem 6:110-122

Prades A, Dornier M, Diop N, Pain JP (2012) Coconut water uses, composition and properties: a review. Fruits 67:87-107

Saini R, Saini JK, Adsul M, Patel AK, Mathur A, Tuli D, Singhania RR (2015) Enhanced cellulase production by Penicillium oxalicum for bio-ethanol application. Bioresour Technol 188:240-246

Singh DP, Trivedi RK (2013) Acid and alkali pretreatment of lignocellulosic biomass to produce ethanol as biofuel. Int J Chem Tech Res 5:727-734

Vigliar R, Sdepanian VL, Fagundes-Neto U (2006) Biochemical profile of coconut water from coconut palms planted in an inland region. J Pediatr 82:308-312

Wang Z, Keshwani DR, Redding AP, Cheng JJ (2010) Sodium hydroxide pretreatment and enzymatic hydrolysis of coastal Bermuda grass. Bioresour Technol 101:3583-3585

Wei SG, Cho EJ, Lee DS, Lee SJ, Lee YJ, Bae HJ (2015) Lignocellulose conversion for biofuel: a new pretreatment 
greatly improves downstream biocatalytic hydrolysis of various lignocellulosic materials. Biotechnol Biofuel 8:1-11

Xu F, Yu J, Tesso T, Dowell F, Wang D (2013) Qualitative and quantitative analysis of lignocellulosic biomass using infrared techniques: a mini-review. Appl Energ 104:801-809
Yang H, Yan R, Chen H, Zheng C, Lee DH, Liang DT (2006) Indepth investigation of biomass pyrolysis based on the three major components: hemicellulose, cellulose and lignin. Energ Fuel 20:388-393 